\title{
Alcohol, sex, age, and the hippocampus
}

\author{
BARBARA WILSON, BRYAN KOLB, LOUISE ODLAND, and IAN Q. WISHAW \\ University of Lethbridge, Lethbridge, Alberta, Canada
}

\begin{abstract}
Chronic alcoholic male and female subjects (aged 19-67) were given a series of neuropsychological tests that had been administered previously to patients with discrete cortical excisions. In the first experiment, the alcoholic subjects were impaired relative to age-matched controls on only block design (from the WAIS) and the copy and recall of the Rey complex figure. Their performance on these tests was equivalent to that of patients with right temporal lobectomies. The subjects performed as well as controls on the WAIS; on various measures of verbal memory, spatial orientation, and verbal fluency; and on the Wisconsin Card Sorting Test. In the second experiment the subjects were given the same verbal and nonverbal memory tests, in addition to the Kimura recurring figures and the Corsi span +1 digit and block tests. The latter tests have proven especially sensitive to hippocampal damage, and the alcoholic patients performed as poorly on the span +1 tests as did patients with temporal lobectomies including the hippocampus. It is suggested that one effect of chronic alcohol abuse is hippocampal dysfunction. This conclusion is consistent with evidence of toxic effects of chronic alcohol intake on hippocampal neurons.
\end{abstract}

Excessive alcohol consumption can be associated with reliable and profound cognitive deficits when it leads to disorders such as Korsakoff's syndrome or alcoholic dementia (e.g., Butters \& Cermak, 1980). Most cases of excessive alcohol intake, however, do not result in such syndromes, but are instead associated with a variety of relatively milder cognitive deficits that can be detected with neuropsychological tests (e.g., Ryan \& Butters, 1986; Oscar-Berman \& Ellis, 1987; Tarter, 1980; Loberg, 1986). Although there are patterns to the cognitive losses reported across studies, there is still significant disagreement in the literature over the cause, nature, and severity of these deficits. The inconsistent results in people with subclinical alcoholic problems are perplexing, inasmuch as various neuroradiological and neuropathological measures in chronic alcohol abusers have shown evidence of cerebral pathology (e.g., Courville, 1955; Ferrer, Fabregues, Rairiz, \& Galofre, 1986; Harper \& Blumbergs, 1982), especially in the frontal cortex, and such pathology would be expected to be related reliably to neuropsychological functioning.

The variability across behavioral studies reflects not only the general difficulty in characterizing the behavioral effects of subtle changes in the nervous system, but also the influence of a myriad of demographic and alcoholismrelated factors that interact to influence test performance (see Klisz \& Parsons, 1979; Ryan \& Butters, 1986). These factors include (1) heterogeneous subject populations with wide variation in variables such as age, sex, occupation, and education; (2) duration of abusive drinking and sub-

This research was supported by an Alberta Mental Health Grant to BK. Reprint requests should be addressed to Bryan Kolb, Department of Psychology, University of Lethbridge, Lethbridge, AB T1K 3M4, Canada. sequent sobriety prior to assessment; and (3) medical complications related to alcohol consumption, such as nutritional deficiency, liver dysfunction, head trauma, and abuse of other drugs. Thus, there is now a view emerging that the neuropsychological consequences of prolonged excessive alcohol consumption result from an interaction of factors, one of which is brain damage resulting directly from the toxic effects of ethanol.

A wide variety of psychological measures have been used to study the cortical functions of alcoholics. The most comprehensive investigations have usually employed some version of the Halstead-Reitan neuropsychological test battery and, more recently, the Luria-Nebraska neuropsychological battery. In the present study we used a composite battery of tests based on results from studies of patients with discrete cortical removals for the relief of intractable epilepsy. These tests have several advantages over other batteries or tests. First, they have been validated on patients with known cerebral injuries, rather than on patients with ill-defined zones of damage from strokes, tumors, closed head injuries, and so forth. Second, the fact that the patients have been tested repeatedly over periods of up to 20 years has permitted refinement of the tests and long-term measures of reliability. Third, information has been accumulated about the effects of damage to very localized areas of the cortex, as additional patients with particular areas of localized damage have become available for assessment. Finally, it is possible to directly compare the test scores of alcoholic patients with those obtained from patients with discrete lesions of different cortical areas. Batteries normed on stroke patients do not allow such localization of symptoms. Thus, the first purpose of this study was to compare the performance of alcoholic patients with the previously reported performance of patients with discrete cortical lesions (Milner, 1970, 
1971). We chose a broad range of tests that have proven sensitive to unilateral focal removals of frontal, temporal, or parietal cortex in addition to general tests of intelligence and memory. We were thus able to compare the performance of our alcoholic patients with the previously published results from patients with focal lesions. It was hoped that this comparison might provide some insight into the nature of the cerebral pathology in chronic alcohol abusers.

Finally, since it has been suggested that both age and sex may interact with alcohol abuse in influencing neuropsychological test results (e.g., Hill, 1982), we recruited subjects ranging in age from 19 to 67 and of both sexes. In this way we hoped to examine the effects that age and sex might have on the performance of our tests.

\section{EXPERIMENT 1}

In Experiment 1 we studied the performance of control and alcoholic subjects on a battery of neuropsychological tests. Our first goal was to determine which tests found deficits in the alcoholic subjects, relative to control subjects. Our second goal was to compare these test results with those results from patients with discrete unilateral frontal, temporal, or parietal lesions.

\section{Method}

Subjects. Forty-nine subjects ( 25 males, 24 females) were recruited from a halfway house for chronic alcoholics and from local Alcoholics Anonymous groups. They were all self-proclaimed alcoholics who reported abusive drinking histories of from 5 to 20 years. (We intentionally recruited subjects with a range of abusive drinking histories to see if length of abuse correlated with test performance.) None had a history of abuse of other drugs, none had obvious tremor at the time of testing and none reported liver disease. All had suffered physical (hospitalization) and/or psychosocial (marital breakdown, loss of employment, conflict with the law, etc.) consequences as a result of their drinking. Half of the female alcoholics completed the Alcohol Use Inventory and showed a mean score on the General Alcoholism scale of 41.7, which places them at the 69 th percentile of scores obtained by over 2,000 male and female alcoholics who constituted the inventory normative sample (Wanberg, Horn, \& Foster, 1977). (The inventory became available to us late in the experiment, so only a portion of our subjects completed the inventory.) None of the subjects had a history of any neurological disease or psychosis and all were free of psychotropic medication at the time of testing. All of the alcoholic subjects had been abstinent for more than 2 months. The 60 control subjects were recruited at the time of testing from a local community college selfhelp group and from university support staff. Older subjects were volunteers from a senior citizens' center. All subjects received payment for their participation. The age, level of education, and sex distribution of all groups are summarized in Table 1.

Tests. Detailed descriptions of the selected tests and the testing procedures have been published previously (Kolb \& Whishaw, 1985), but some brief descriptions will be provided here. Testing was carried out in two 2-h sessions. In the first session, each subject was given the Wechsler Adult Intelligence Scale (WAIS) and the Wechsler Memory Scale. Following the procedure of Milner (1975), the subjects were then given a delayed recall test (approximately $30 \mathrm{~min}$ after the initial recall test) of the logical stories, paired associates, and geometric designs of the memory scale. The second testing session began with the Dichotic words test. Three pairs of two different monosyllabic words were presented, one word to each ear, simultaneously. The subject was asked to recall as many of the six words as possible, in any order. A total of 20 series of the three pairs of words were presented in all. The subject's score was the total number of words recalled from each ear. For the Rey complex figure, the subjects were presented with a printed copy of the Rey figure and asked to copy the figure as exactly as they could.

Forty-five minutes later the subjects were asked (without advance warning) to reproduce as much of the figure as they could remember (Taylor, 1969). Objective scoring criteria can be found in Lezak (1983). The Mooney closure test consists of a series of 26 incomplete representations of faces in which the highlights and shadows are exaggerated but the contour is poorly defined. The subject is allowed up to $30 \mathrm{sec}$ in which to discover the face and state the sex and appropriate age of the person depicted (Milner, 1975,1980 ). In the left/right differentiation test the subjects are shown a series of drawings of body parts and clothing and are asked to determine whether each is on the left or right side. In the Body placing test, the subject is shown a series of drawings of a person on which various body parts are numbered; the task is to point to the location of each of the numbered parts on the subject's own body (Semmes, Weinstein, Ghent, \& Teuber, 1963). Verbal fluency is assessed using two different tests: Chicago word fluency and Newcombe word fluency. In the Chicago word fluency test, the subject is asked to write down as many words beginning with a particular letter (e.g., S) as he/she can in $5 \mathrm{~min}$, and as many words beginning with another letter but having only four letters (e.g., C---) in 4 min (Milner, 1964). In the Newcombe fluency test, the subject is asked to give orally the names of as many different animals as possible in $1 \mathrm{~min}$ and the names of as many objects as possible in $1 \mathrm{~min}$, and then to give in alternation as many bird/color/bird/color names as possible in $1 \mathrm{~min}$ (Newcombe, 1969). Finally, in the Wisconsin card sorting test (Milner, 1964), the subject is presented with 4 stimulus cards bearing designs that differ in color, form, or number. The subject's task is to sort a pack of cards that vary along these dimensions. The correct sorting strategy is changed, without warning, every time 10 consecutive cards are sorted correctly. Testing ends when the subject either completes six categories or sorts 128 cards, whichever comes first. The subject's score is the number of correct categories solved as well as the number of perseverative errors made.

Statistical analysis. In view of the large number of possible comparisons and therefore the problem of high error rates in our analysis, we chose to follow the advice of Keppel (1982). We began by creating a matrix that correlated all of the demographic and neuropsychological variables with one another. Then we did analyses of variance on those variables that were significant, since we wished to reduce the likelihood of making a Type I error when performing so many statistical analyses. Finally, we used a stepwise regression analysis on all subjects in order to predict alcohol versus control grouping, followed by a regression to predict years of drinking in the alcoholic subjects.

\section{Results}

The alcoholic subjects performed as well as the controls on nearly every test, differing significantly only on block design and the copy and recall of the Rey figure. Table 1 summarizes the mean performance on each test and, where appropriate, compares our subjects' performance with that of patients with discrete cortical lesions.

Table 2 summarizes the significant correlations (twotailed $p s<.01)$ and shows that alcohol abuse correlated with performance on block design, delayed paired associates, and copy and recall of the Rey figure. None of these variables correlated with sex, but most correlated with age. Furthermore, age correlated with many other vari- 
Table 1

Summary of Subjects, Scores, and Tests in Experiment 1

\begin{tabular}{|c|c|c|c|c|c|c|}
\hline \multirow[b]{2}{*}{ Variable } & \multicolumn{2}{|c|}{ Controls } & \multicolumn{2}{|c|}{ Alcoholics } & \multirow[b]{2}{*}{ Neurological } & \multirow[b]{2}{*}{ Reference } \\
\hline & $M$ & $S D$ & $M$ & $S D$ & & \\
\hline \multicolumn{7}{|l|}{ Demographic } \\
\hline $\begin{array}{l}\text { Age } \\
\text { Education } \\
\text { Years drinking } \\
\text { Months sober }\end{array}$ & $\begin{array}{l}41.9 \\
11.8\end{array}$ & $\begin{array}{r}13.8 \\
2.4\end{array}$ & $\begin{array}{l}41.4 \\
10.2 \\
10.0 \\
20.0\end{array}$ & $\begin{array}{r}11.0 \\
2.1 \\
5.9 \\
24.3\end{array}$ & & \\
\hline \multicolumn{7}{|c|}{ Wechsler Adult Intelligence Scale } \\
\hline $\begin{array}{l}\text { Full scale IQ } \\
\text { Verbal IQ } \\
\text { Performance IQ } \\
\text { Block design }\end{array}$ & $\begin{array}{r}117.0 \\
114.8 \\
117.5 \\
11.9\end{array}$ & $\begin{array}{r}11.3 \\
11.6 \\
11.6 \\
2.5\end{array}$ & $\begin{array}{r}114.0 \\
113.8 \\
114.0 \\
9.8\end{array}$ & $\begin{array}{c}10.7 \\
11.6 \\
10.7 \\
2.5 *\end{array}$ & & \\
\hline \multicolumn{7}{|l|}{ Temporal Lobe } \\
\hline $\begin{array}{l}\text { Wechsler memory scale } \\
\text { Memory passages } \\
\text { Delayed memory passages } \\
\text { Paired associates } \\
\text { Delayed paired associates } \\
\text { Stories + passages } \\
\text { Drawings } \\
\text { Delayed drawings } \\
\text { Rey recall } \\
\text { Dichotic total } \\
\text { Dichotic left } \\
\text { Dichotic right }\end{array}$ & $\begin{array}{r}116.2 \\
9.8 \\
15.3 \\
16.7 \\
9.4 \\
27.1 \\
10.9 \\
9.9 \\
21.5 \\
51.1 \\
18.5 \\
32.6\end{array}$ & $\begin{array}{r}15.4 \\
2.4 \\
4.7 \\
2.9 \\
1.0 \\
\\
2.7 \\
3.3 \\
5.2 \\
10.1 \\
9.0 \\
9.0\end{array}$ & $\begin{array}{r}111.1 \\
8.9 \\
14.4 \\
16.2 \\
9.2 \\
25.4 \\
9.6 \\
7.3 \\
14.8 \\
51.2 \\
14.2 \\
37.0\end{array}$ & $\begin{array}{r}12.6 \\
2.3 \\
4.6 \\
3.3 \\
0.9 \\
\\
2.9 \\
3.5 \\
5.6^{*} \\
7.4 \\
11.0 \\
10.1\end{array}$ & $14.0(\mathrm{R})$ & Milner (1967) \\
\hline \multicolumn{7}{|l|}{ Temporal/Parietal } \\
\hline $\begin{array}{l}\text { Rey copy } \\
\text { Newcombe fluency I } \\
\text { Newcombe fluency II } \\
\text { Newcombe fluency III } \\
\text { Left/right } \\
\text { Mooney closure } \\
\text { Digit span }\end{array}$ & $\begin{array}{l}35.2 \\
26.1 \\
20.9 \\
15.7 \\
50.9 \\
21.6 \\
10.0\end{array}$ & $\begin{array}{l}1.3 \\
6.8 \\
4.9 \\
3.3 \\
5.7 \\
2.5 \\
2.5\end{array}$ & $\begin{array}{l}32.8 \\
24.2 \\
20.4 \\
15.2 \\
47.5 \\
21.4 \\
10.4\end{array}$ & $\begin{array}{l}3.6^{*} \\
5.4 \\
4.3 \\
3.4 \\
7.6 \\
2.0 \\
2.6\end{array}$ & $\begin{array}{r}30.0(\mathrm{R}) \\
22.0(\mathrm{~L}) \\
15.0(\mathrm{~L}) \\
11.0(\mathrm{~L}) \\
30.0(\mathrm{~L}) \\
18.3(\mathrm{R}) \\
6.8(\mathrm{~L})\end{array}$ & $\begin{array}{l}\text { Taylor (1969) } \\
\text { Newcombe (1969) } \\
\text { Newcombe (1969) } \\
\text { Newcombe (1969) } \\
\text { Kolb (unpublished) } \\
\text { Milner (1980) } \\
\text { Kolb (unpublished) }\end{array}$ \\
\hline \multicolumn{7}{|l|}{ Frontal Lobe } \\
\hline $\begin{array}{l}\text { Wisconsin card sorting } \\
\text { Chicago word fluency } \\
\text { Semmes body placing }\end{array}$ & $\begin{array}{r}5.6 \\
56.1 \\
34.1\end{array}$ & $\begin{array}{r}1.1 \\
19.2 \\
2.1\end{array}$ & $\begin{array}{r}5.2 \\
54.2 \\
33.0\end{array}$ & $\begin{array}{r}1.1 \\
18.6 \\
3.5\end{array}$ & $\begin{array}{l}3.3 \\
35.0 \\
24.0(\mathrm{~L})\end{array}$ & $\begin{array}{l}\text { Milner }(1964) \\
\text { Milner }(1964) \\
\text { Teuber }(1964)\end{array}$ \\
\hline
\end{tabular}

Note-L $=$ left hemisphere; $\mathrm{R}=$ right hemisphere. ${ }^{*}$ Differs from control $(p<.05$ or better).

ables that were not correlated with alcohol (see Table 2). Analyses of variance (group $\times$ sex) revealed significant main effects of group on block design $[F(1,105)=15.4$, $p<.001]$, Rey copy $[F(1,105)=21.9, p<.01]$, and Rey recall $[F(1,105)=37.8, p<.001]$. No other main effects or interactions were significant $(p s>.10)$.

Stepwise regression was performed on the entire subject population to predict alcohol abuse, but years of drinking and months of sobriety were deleted from the analysis, since all controls had scores of zero, so these data obviously predict alcoholism. The regression $(\min F=4.0$, $p<.05$ ) found the following variables to predict alcohol grouping: Step 1, Rey recall $\left(r^{2}=.26\right)$; Step 2, education $\left(r^{2}=.35\right)$; Step 3 , digit span $\left(r^{2}=.39\right)$; Step 4 , block design $\left(r^{2}=.42\right)$; Step 5 , age $\left(r^{2}=.45\right)$. Thus, the best predictor of alcoholism is recall of the Rey figure, which is reasonable given the test scores summarized in Table 1.
Table 2 also summarizes the correlations found when the alcoholic group was analyzed separately. Of particular interest are the correlations between years of drinking and test performance and between age and test performance. It can be seen that whereas years of drinking significantly correlated with some test scores, it did not correlate with performance on block design or recall of the Rey figure, both of which were performed poorly by alcoholics. A stepwise regression on the alcoholic subjects was run to predict years of drinking, since there were several correlations between years of drinking and test performance. The results were as follows: Step 1, Rey copy $\left(r^{2}=.20\right)$; Step 2 , paired associate learning $\left(r^{2}=.24\right)$. Finally, it is noteworthy that although years of drinking correlated with several tests, it did not correlate with block design or Rey recall, which were the tests that best discriminated alcoholics from controls, and months of sobriety failed to correlate with any measure, 
Table 2

Summary of Significant Correlations

\begin{tabular}{|c|c|c|c|c|c|c|c|}
\hline \multirow[b]{3}{*}{ Variable } & \multirow{2}{*}{\multicolumn{3}{|c|}{ Total Population }} & \multicolumn{4}{|c|}{ Alcoholics } \\
\hline & & & & \multirow{2}{*}{$\begin{array}{c}\text { Years } \\
\text { Drinking }\end{array}$} & \multirow{2}{*}{$\begin{array}{c}\text { Months } \\
\text { Sober }\end{array}$} & \multirow[b]{2}{*}{ Sex } & \multirow[b]{2}{*}{ Age } \\
\hline & Alcohol & Sex & Age & & & & \\
\hline \multicolumn{8}{|l|}{ Demographic } \\
\hline Age & - & - & - & - & - & - & - \\
\hline Sex & - & - & - & - & - & - & - \\
\hline Education & +.37 & - & - & - & - & - & - \\
\hline Years Drinking & -.79 & - & - & - & - & -.55 & +.49 \\
\hline Months Sober & -.50 & - & - & - & - & - & +.36 \\
\hline \multicolumn{8}{|c|}{ Wechsler Adult Intelligence Scale } \\
\hline Block design & +.36 & - & -.34 & - & - & - & - \\
\hline Digit symbol & - & - & -.35 & -.47 & - & - & -.43 \\
\hline \multicolumn{8}{|l|}{ Temporal Lobe } \\
\hline Wechsler raw score & - & - & -.26 & -.50 & - & - & -.41 \\
\hline Memory passages & - & - & - & - & - & - & - \\
\hline Delayed memory passages & - & - & - & - & - & - & - \\
\hline Paired associates & - & +.26 & -.36 & -.46 & - & - & -.56 \\
\hline Delayed paired associates & +.37 & - & -.31 & -.39 & - & - & - \\
\hline Drawings & - & - & -.29 & - & - & - & - \\
\hline Delayed drawings & - & - & -.37 & - & - & - & -.57 \\
\hline Rey recall & +.52 & - & -.37 & - & - & - & -.36 \\
\hline Dichotic total & - & - & -.28 & - & - & - & - \\
\hline Dichotic left & - & - & - & - & - & - & - \\
\hline Dichotic right & - & - & - & - & - & - & - \\
\hline \multicolumn{8}{|l|}{ Parietal Lobe } \\
\hline Rey copy & +.44 & - & -.26 & -.52 & - & - & -.44 \\
\hline Newcombe fluency & - & - & - & - & - & - & - \\
\hline Left/Right & - & - & - & - & - & - & - \\
\hline Mooney closure & - & - & -.33 & - & - & - & - \\
\hline \multicolumn{8}{|l|}{ Frontal Lobe } \\
\hline Wisconsin card sorting & - & - & - & - & - & -.51 & - \\
\hline Chicago word fluency & +.27 & - & - & - & - & - & - \\
\hline Semmes body placing & - & - & - & - & - & - & - \\
\hline
\end{tabular}

although perhaps this latter finding resulted from too short a period of abstinence (e.g., Markowitsch, Kessler, \& Denzler, 1986).

In order to investigate the effects of normal aging on our control population, we created a correlation matrix on just the control subjects. The significant correlations (two-tailed $p \mathrm{~s}<.01$ ) with age were block design $(r=-.44)$, digit symbol $(r=-.40)$, Wechsler memory scale drawings $(r=-.35)$, delayed recall of the drawings $(r=-.33)$, paired associates $(r=-.33)$, delayed paired associates $(r=-.42)$, recall of the Rey figure $(r=-.53)$, Mooney closure $(r=-.52)$, total dichotic words $(r=-.38)$, and dichotic words to the left ear $(r=-.46)$. These results are very similar to the correlations with the total group (Table 2). Stepwise regression was performed to predict age in the control subjects and revealed the following: Step 1, Rey recall $\left(r^{2}=.28\right)$; Step 2, Mooney closure $\left(r^{2}=.47\right)$; Step 3, dichotic words to the left ear $\left(r^{2}=.54\right)$. The conclusion to be drawn from these results is that although alcohol and aging negatively affect performance on several of the same tests, aging affects many tests that alcohol does not.
To summarize, the main results of this experiment showed that alcoholic subjects performed more poorly on the copy and recall of the Rey figure and on block design than on other tests. Their performance on the Rey figure is especially interesting, since the mean of the alcoholic subjects is equivalent to the mean performance of patients with right temporal lobectomies. In contrast, as reported in many previous studies, alcoholics did not differ from controls on most measures, especially on the verbal tests.

\section{EXPERIMENT 2}

Our first experiment showed a pattern of test results most reminiscent of patients with right temporal lobe lesions and led us to wonder how alcoholics would perform on other tests of right temporal lobe function. The purpose of Experiment 2 was to look at the possibility that alcoholics might be particularly impaired on tests sensitive to the integrity of the hippocampal formation. We are unaware of previous studies of this sort, but the possibility that alcohol may have a toxic effect on the hippocampus has been suggested by neuroanatomical studies 
(e.g., Riley \& Walker, 1978; Walker, Barnes, Zornetzer, Hunter, \& Kubanis, 1980). Hence, we used two tests devised by Corsi (see Milner, 1970) that are uniquely sensitive to damage to the left and right hippocampus.

The new tests included the Corsi span and span +1 tests (Milner, 1974) and the Kimura recurring figures (Kimura, 1963). The Corsi digit and block spans are sensitive to left and right parietal damage, respectively; the Corsi digit span +1 and block span +1 are sensitive to left and right hippocampal damage, respectively (Milner, 1970, 1971); and the Kimura recurring figures are sensitive to right temporal lobe damage (Kimura, 1963). These tests had been given previously to patients with temporal lobe removals, at the Montreal Neurological Institute, for the relief of intractable epilepsy. At the time of surgery the surgeon drew the extent of removal and indicated the amount of hippocampal removal, if any. It has thus been possible for Milner and her associates to correlate behavior with the extent of hippocampal damage in large numbers $(>100)$ of patients over the years. We took advantage of this in the present experiment and compared our alcoholic patients to those excision patients studied in Montreal.

\section{Method}

Subjects. The subject sample consisted of 18 chronic alcoholics ( 10 males and 8 females) recruited from a halfway house and local
Alcoholics Anonymous groups and 20 nonalcoholic volunteers ( 10 males and 10 females) recruited from the local community. Subjects were matched on age and education (Table 3). Neither alcoholic nor control subjects reported any history of neurological disease and none had a history of abuse of drugs other than alcohol. All of the subjects completed the Alcohol Use Inventory to determine history of alcohol use. The alcoholics' mean score was 47.6 (84th percentile) and the controls' mean score was 4.7 ( 7 th percentile). There was no overlap in the scores of the two groups and the respective means indicate a history of alcohol abuse in the alcoholics but not in the controls (Wanberg et al., 1977). All of the alcoholic subjects had experienced alcohol-related blackouts, which lasted several hours, whereas only two controls had experienced a blackout (one incident of less than $1 \mathrm{~h}$ in each case).

Tests. The subjects were given the Wechsler Memory Scale (Form I), delayed recall of the Wechsler stories, paired associates and drawings, and the Rey complex figure as in Experiment 1. They were also given the following tests: In the Kimura recurring figures test, the subject is shown a series of 20 cards, each of which depicts an unfamiliar design (geometric and nonsense figures). The subject is then presented a series of 120 cards in which the original designs are interspersed throughout the new cards. It is the task of the subject to indicate whether each design has been seen before. In the digit span test, the subjects are asked to repeat series of digits forward. Two attempts are given at each length and the span is established when both series at a particular length are incorrect. The block span test is an analogue of the digit span in which nine blocks (roughly $2.5 \mathrm{~cm}$ per side) are affixed to a black board in a random order (see diagram in Kolb \& Whishaw, 1985, p. 487). For each series the examiner taps the blocks in a prearranged sequence and the subject's task is to copy the tapping pattern. Span

Table 3

Summary of Test Scores and Correlations in Experiment 2

\begin{tabular}{|c|c|c|c|c|c|}
\hline \multirow[b]{2}{*}{ Variable } & \multicolumn{2}{|c|}{ Controls } & \multicolumn{2}{|c|}{ Alcoholics } & \multirow{2}{*}{$\begin{array}{l}\text { Correlations } \\
\text { (Alcoholics) }\end{array}$} \\
\hline & $M$ & $S D$ & $M$ & $S D$ & \\
\hline \multicolumn{6}{|l|}{ Demographic } \\
\hline $\begin{array}{l}\text { Age } \\
\text { Education } \\
\text { Years drinking } \\
\text { General Alcoholism scale } \\
\text { Wechsler memory scale }\end{array}$ & $\begin{array}{r}36.7 \\
11.6 \\
\\
4.7 \\
119.4\end{array}$ & $\begin{array}{r}16.0 \\
3.1 \\
\\
6.2 \\
14.0\end{array}$ & $\begin{array}{r}37.6 \\
12.6 \\
13.9 \\
47.6 \\
107.2\end{array}$ & $\begin{array}{c}11.0 \\
2.0 \\
6.4 \\
13.0^{*} \\
20.0\end{array}$ & $\begin{array}{l}+.85 \\
+.92 \\
-.32\end{array}$ \\
\hline \multicolumn{6}{|l|}{ Verbal Memory } \\
\hline $\begin{array}{l}\text { Paired associates } \\
\text { Delayed paired associates } \\
\text { Memory passages } \\
\text { Delayed memory passages }\end{array}$ & $\begin{array}{r}18.0 \\
9.6 \\
16.8 \\
17.1\end{array}$ & $\begin{array}{l}1.2 \\
0.9 \\
4.8 \\
6.7\end{array}$ & $\begin{array}{r}17.0 \\
9.4 \\
20.1 \\
14.8\end{array}$ & $\begin{array}{l}2.6 \\
1.2 \\
7.9 \\
5.6\end{array}$ & \\
\hline \multicolumn{6}{|l|}{ Nonverbal Memory } \\
\hline $\begin{array}{l}\text { Drawings } \\
\text { Delayed drawings } \\
\text { Rey copy } \\
\text { Delayed Rey } \\
\text { Kimura recurring figures }\end{array}$ & $\begin{array}{l}11.3 \\
10.2 \\
35.3 \\
22.6 \\
24.3\end{array}$ & $\begin{array}{l}2.7 \\
3.2 \\
1.5 \\
6.0 \\
6.4\end{array}$ & $\begin{array}{r}8.9 \\
6.4 \\
34.2 \\
16.6 \\
21.4\end{array}$ & $\begin{array}{l}2.4^{*} \\
2.9^{*} \\
1.4^{*} \\
5.5^{*} \\
6.1\end{array}$ & $\begin{array}{l}-.40 \\
-.51 \\
-.41 \\
-.41\end{array}$ \\
\hline \multicolumn{6}{|l|}{ Verbal Spans } \\
\hline $\begin{array}{l}\text { Digit span } \\
\text { Digit span }+1 \text { recurring } \\
\text { Digit span }+1 \text { nonrecurring }\end{array}$ & $\begin{array}{r}6.9 \\
63.0 \\
35.6\end{array}$ & $\begin{array}{r}0.6 \\
25.0 \\
11.0\end{array}$ & $\begin{array}{r}6.3 \\
38.7 \\
28.9\end{array}$ & $\begin{array}{l}1.1 \\
31.0^{*} \\
16.0\end{array}$ & -.39 \\
\hline \multicolumn{6}{|l|}{ Nonverbal spans } \\
\hline $\begin{array}{l}\text { Block span } \\
\text { Block span }+1 \text { Recurring } \\
\text { Block span }+1 \text { nonrecurring }\end{array}$ & $\begin{array}{r}5.7 \\
62.9 \\
35.6\end{array}$ & $\begin{array}{r}0.7 \\
14.9 \\
6.9\end{array}$ & $\begin{array}{r}5.6 \\
23.0 \\
29.1\end{array}$ & $\begin{array}{c}0.7 \\
20.0^{*} \\
9.9\end{array}$ & -.74 \\
\hline
\end{tabular}

Note-Only the significant correlation coefficients $(p<.01)$ are reported. $*$ Differs significantly from control $(p<.01$ or better). 
is determined as in the digit span. For each of these tests the span +1 is one item longer than the span. For this test the subject is given 24 trials of digit or tapping sequences in which every third series is repeated. Thus, the subjects can be scored separately on the recurring and nonrecurring items.

\section{Results}

The main results were as follows: (1) Alcoholic subjects were impaired at recall of the Wechsler drawings and the Rey figure but not on the recognition of the Kimura recurring figures, and (2) alcoholic subjects were severely impaired on the recurring items in the span +1 tests but performed normally on the nonrecurring items.

Table 3 summarizes the data from all of the tests, as well as the significant correlations (two-tail, $p<.01$ ) in the correlation matrix. It can be seen that, as in Experiment 1 , Rey copy and Rey recall correlate with alcohol, but so do Wechsler drawings and delayed drawings. More importantly, both of the span +1 recurring items correlated highly with alcohol in this experiment. Analyses of variance were performed as before, with main effects of group and sex separated. The main effect of group was significant for Wechsler drawings $[F(1,34)=7.9$, $p<.01]$, recall of Wechsler drawings $[F(1,34)=13.6$, $p<.01]$, Rey copy $[F(1,34)=5.7, p<.01]$, Rey recall $[F(1,34)=10.4, p<.01]$, recurring digits $[F(1,34)=$ $6.8, p=.013]$, and recurring blocks $[F(1,34)=46.5$, $p<.01]$. The block span +1 was clearly the test most poorly performed by the alcoholic subjects. A stepwise regression to predict alcohol abuse, done on all of the data except years of drinking and general alcoholism score, found only one significant variable, namely, recurring blocks $\left(r^{2}=.57\right)$, which obviously accounted for a large amount of the variance.

Figure 1 compares the performance of the alcoholic subjects with that of patients with unilateral temporal lobectomies that included the hippocampus. It is apparent that the alcoholic subjects performed at the level of the hippocampal patients, the major difference being that the alcoholic subjects were impaired on both digit and block tests, whereas the left hippocampal patients were impaired only on digits and the right hippocampal patients were impaired only on blocks.

\section{DISCUSSION}

The principal finding of our study is that chronic alcoholics were inferior to matched control subjects on two tests that are specifically sensitive to hippocampal damage in neurological patients. We recognize that the poor performance of alcoholics on these two tasks could have been caused by factors other than the putative toxic effects of alcohol on the hippocampus (Riley \& Walker, 1978), but we are inclined to propose that the deficit in the alcoholics is most likely due to hippocampal damage resulting from alcohol abuse. For instance, although the poor performance of our alcoholic subjects on the span +1 tests may have resulted from nonneurological factors, such as low interest in the tests, our patients performed normally on
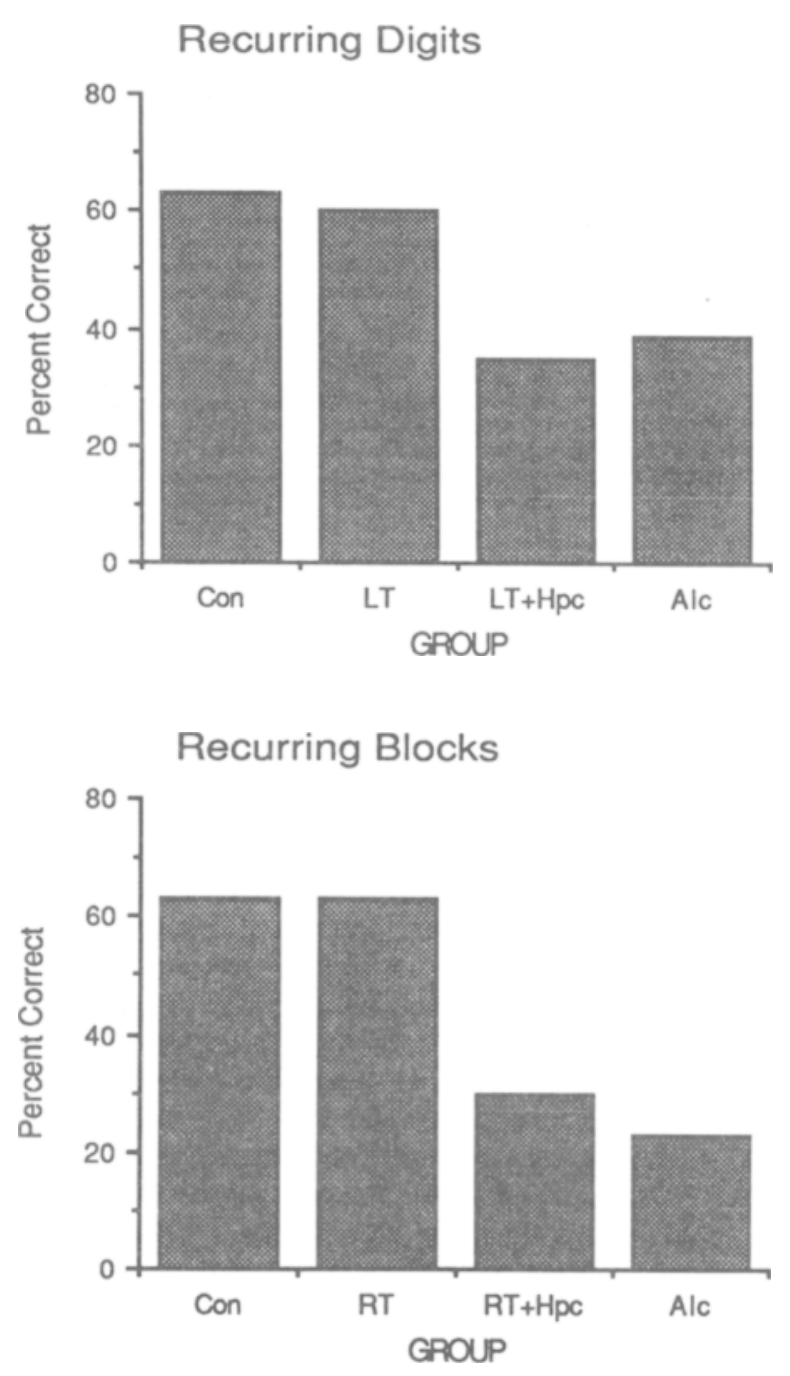

Figure 1. Mean percent correct performance of the control and alcoholic subjects in the current experiment compared with the data from temporal lobe patients previously published by Milner (1970, 1971). The temporal lobe patients had either the temporal cortex alone or the temporal cortex plus the hippocampus removed. The alcoholic patients performed as poorly as the patients with hippocampus removed. Con $=$ control; $L T=$ left temporal; $R T=$ right temporal; LT + Hpc = left temporal plus hippocampal damage; $\mathbf{R T}+\mathrm{Hpc}=$ right temporal plus hippocampal damage; Alc $=$ alcoholic.

most other tests that we administered. Furthermore, similar arguments could be used in the case of the hippocampal patients.

Neuropsychological studies of female alcoholics are few, but available evidence suggests that there are sex differences in alcoholic drinking patterns (Beckman, 1975); in the effects of alcohol on morbidity and mortality (Hill, 1982), the effects being more severe in women; and in the patterns of cognitive deficits in brain-damaged adults (Kimura, 1983; McGlone, 1980). This evidence suggests the possibility of sex-related differences in the neuropsychological effects of alcohol abuse, but we could find no evidence of a sex difference in the neuropsycho- 
logical functions of male and female alcoholics. This result is generally consistent with the few previous reports on female alcoholics (e.g., Fabian, Parsons, \& Sheldon, 1984; Silberstein \& Parsons, 1980).

Our final finding is that although age did correlate with many of the same tests as did alcohol, age showed equally high correlations with many tests that were not correlated with alcohol. Comparisons of the stepwise regressions to predict alcohol or aging did load on the same first variable (Rey recall), but the subsequent loadings were totally different. Furthermore, the correlation between age and the recurring blocks in the span +1 test was only .1, which is not significantly different from zero. We therefore conclude that although aging and alcohol share some similarities in their behavioral effects on the brain, our data are not supportive of the idea that alcohol speeds up the normal aging process (e.g., Ryan \& Butters, 1980). This conclusion has been reached by others on different grounds (e.g., Grant, Adams, \& Reed, 1984).

Our results are relevant to hypotheses regarding the neuropsychological abnormalities observed in alcoholics, even though our experiments were not designed to test them specifically. First, they offer no evidence to support the hypothesis that alcohol abuse leads to diffuse cerebral dysfunction. The alcoholics' performance both on general intelligence tests and on most of the neuropsychological tests was very similar to that of age-matched controls; these results are consistent with those of numerous other studies (e.g., Parsons, 1974; Tarter, 1980). Second, our results are not inconsistent with the hypothesis of a right-hemisphere dysfunction in alcoholics. Like others (e.g., Ryan \& Butters, 1986; Tarter, 1980), we found an impairment on the block design test of the WAIS and on tests of nonverbal memory. We are reluctant to conclude solely on the basis of this evidence that alcoholics have lateralized brain damage because: (1) Reported pathology does not appear to be specific to the right hemisphere; (2) the "right-hemisphere tasks"' are likely to rely on skills that are less well practiced than verbal tasks, so that the threshold for an impairment is lower for the nonverbal tasks; and (3) we found no deficit on the Kimura recurring figures, which are normally affected by right temporal lobe damage (but are not affected by additional damage to the hippocampus). Third, our results do not support the idea that chronic alcohol ingestion produces primarily a frontolimbic dysfunction (e.g., Berglund \& Ingvar, 1976; Courville, 1955; Samson, Baron, Feline, Bories, \& Crouzel, 1986; Tarter, 1975, 1980). None of the tests sensitive to frontal lobe damage were performed more poorly by alcoholic subjects, a result found by others as well (e.g., Eckardt, Parker, Noble, Poulter, \& Gottschalk, 1979; Obalia, Leber, \& Parsons, 1981). Still, in view of the evidence on diencephalic amnesia (e.g., Squire, 1982), the pathology of which includes some of the primary afferents to the frontal lobe, the frontolimbic hypothesis may still be worth investigating, possibly with emphasis on tests of frontal lobe func- tion in memory, which was not specifically addressed in this study (e.g., Schacter, 1987).

In conclusion, although we are proposing that chronic alcohol abuse leads to specific hippocampal deficits, we must offer a word of caution. The strength of our tests is that they are known to be sensitive to relatively specific cortical regions. Their weakness is that they are not designed to measure subcortical functions, which may be disrupted by chronic alcohol abuse. Furthermore, we have no guarantee that the evidence of cognitive deficits can be taken as evidence of specific pathology. For example, it is possible that people with deficits on tests such as the Rey figure or span +1 are prone to become alcoholic. Nothing in our tests or experiments indicates what is cause and what is effect. Notwithstanding these constraints, we believe that the possibility of relatively specific deficits in hippocampal function resulting from alcohol abuse warrants serious consideration and further study.

\section{REFERENCES}

Beckman, L. L. (1975). Women alcoholics: A review of social and psychological studies. Journal of Studies on Alcohol, 36, 797-824.

Berglund, M., \& Ingvar, D. (1976). Cerebral blood flow and its regional distribution in alcoholism and Korsakoff's psychosis. Journal of Studies on Alcohol, 37, 586-597.

Butters, N., \& CERmak, L. S. (1980). Alcoholic Korsakoffs syndrome. New York: Academic Press.

Courville, C. B. (1955), Effects of alcohol on the nervous system of man, Los Angeles: San Lucas Press.

Eckardt, M. J., Parker, E. S., Noble, E. P., Poulter, C. P., \& GotTschalK, L. A. (1979). Changes in neuropsychological performance during treatment for alcoholism. Biological Psychiatry, 14, 943-954.

Fabian, M. S., Parsons, O. A., \& Sheldon, M. D. (1984). Effects of gender and alcoholism on verbal and visual-spatial learning. Journal of Nervous \& Mental Disease, 172, 16-20.

Ferrer, I., Fabregues, I., Rairiz, J., \& Galofre, E. (1986). Decreased number of dendritic spines on cortical pyramidal neurons in human chronic alcoholism. Neuroscience Letters, 69, 115-119.

Grant, I., Adams, K., \& ReED, R. (1984). Aging, abstinence, and medical risk factors in the prediction of neuropsychological deficit among long-term alcoholics. Archives of General Psychiatry, 41, 710-718.

Harper, C. G., \& Blumbergs, P. C. (1982). Brain weight in alcoholics. Journal of Neurology, Neurosurgery, \& Psychiatry, 45, 838-840.

HılL, S. Y. (1982). Biological consequences of alcoholism and alcoholrelated problems among women. In Alcohol and Health Monograph No. 4 (DHHS Publication No. 82-1193, pp 43-73). Washington, DC: U.S. Government Printing Office.

KEPPEL, G. (1982). Design and analysis: A researcher's handbook. New York: Prentice-Hall.

Kimura, D. (1963). Right temporal-lobe damage: Perception of unfamiliar stimuli after damage. Archives of Neurology, 8, 264-271.

KimuRA, D. (1983). Sex differences in cerebral organization for speech and praxic functions. Canadian Journal of Psychology, 37, 19-35.

KLISz, D., \& Parsons, O. A. (1979). Cognitive functioning in alcoholics: The role of subject attrition. Journal of Abnormal Psychology, 88, 268-276.

KolB, B. \& Whishaw, 1. Q. (1985). Fundamentals of human neuropsychology (2nd ed.). New York: W. H. Freeman.

LEzAK, M. (1983). Neuropsychological assessment (2nd ed.). New York: Oxford University Press.

LOBERG, T. (1986). Neuropsychological findings in the early and middle phases of alcoholism. In I. Grant \& K. M. Adams (Eds.), Neu- 
ropsychological assessment of neuropsychiatric disorders (pp. 415440). New York: Oxford University Press.

Markowitsch, H. J., Kessler, J., \& Denzler, P. (1986). Recognition memory and psychophysiological responses to stimuli with neutral or emotional content: A study of Korsakoff patients and recently detoxified and long-term abstinent alcoholics. International Journal of Neuroscience, 29, 1-35.

MCGlone, J. (1980). Sex differences in human brain asymmetry; A critical survey. Behavioral \& Brain Sciences, 3, 215-263.

Milner, B. (1964). Some effects of frontal lobotomy in man. In J. M. Warren \& K. Akert (Eds.), The frontal granular cortex and behavior (pp. 313-334). New York: McGraw-Hill.

MiLNER, B. (1967). Brain mechanisms suggested by studies of the temporal lobes. In F. L. Darley (Ed.), Brain mechanisms underlying speech and language (pp. 122-145). New York: Grune \& Stratton.

MilneR, B. (1970). Memory and the medial temporal regions of the brain. In K. H. Pribram \& D. E. Broadbent (Eds.), Biological bases of memory (pp. 29-50). New York: Academic Press.

MiLNER, B. (1971). Interhemispheric differences in the localization of psychological processes in man. British Medical Bulletin, 27, 272-277.

MILNER, B. (1974). Hemispheric specialization. In F. O. Schmit \& F. G. Worden (Eds.), The Neurosciences: Third study Program (pp. 7589). Cambridge: MIT Press.

Milner, B. (1975). Psychological effects of focal epilepsy and its neurosurgical management. Advances in Neurology, 8, 299-321.

MILNER, B. (1980). Complementary functional specialization of the human cerebral hemispheres. Pontificiae Academiae Scientianum Scripta Varia, 45, 601-625.

Newcombe, F. (1969). Missile wounds of the brain. London: Oxford University Press.

Obalia, R., Leber, W. R., \& Parsons, O. A. (1981). Assessment of neuropsychological functions in chronic alcoholics using a standardized version of Luria's neuropsychological technique. International Journal of Neuroscience, 14, 85-93.

Oscar-Berman, M., \& Ellis, R. J. (1987). Cognitive deficits related to memory impairments in alcoholism. In M. Galanter (Ed.), Recent developments in alcoholism (pp. 59-80). New York: Plenum.

PARSons, O. A. (1974). Brain damage in alcoholics: Altered states of unconsciousness. Alcohol Technical Reports, 2, 93-105.

Ril.eY, J. N., \& WALKER, D. W. (1978). Morphological alterations in hippocampus after long-term alcohol. Science, 201, 646-648.
RyAN, C., \& ButTERS, N. (1980). Learning and memory impairments in young and old alcoholics: Evidence for the premature aging hypothesis. Alcoholism Clinical Experimental Research, 4, 288-293.

RYAN, C., \& ButTERs, N. (1986). The neuropsychology of alcoholism. In D. Wedding, A. MacNiell-Horton, Jr., \& J. Webster (Eds.), The neuropsychological handbook: Behavioral and clinical perspectives (pp. 376-409). New York: Springer.

Samson, Y., Baron, J.-C., Feline, A., Bories, J., \& Crouzel, S. (1986). Local cerebral glucose utilization in chronic alcoholics: A position tomographic study. Neurology, Neurosurgery \& Psychiatry, 49, 1165-1170.

SCHACTER, D. L. (1987). Memory, amnesia, and frontal lobe dysfunction. Psychobiology, 15, 21-36.

Semmes, L., Weinstein, S., Ghent, L., \& Teuber, H.-L. (1963). Impaired orientation in personal and extra-personal space. Brain, 86, 747-772.

Silberstein, J. A., \& Parsons, O. A. (1980). Neuropsychological impairment in female alcoholics. Currents in Alcoholism, 7, 481-496.

SQUIRE, L. R. (1982). The neuropsychology of human memory. Annual Review of Neuroscience, 5, 241-273.

TARTER, R. E. (1975). Psychological deficit in chronic alcoholism: A review. International Journal of Addictions, 10, 327-368.

TARTER, R. E. (1980). Brain damage in chronic alcoholics: A review of psychological evidence. In $\mathrm{O}$. Richter (Ed.), Addiction and brain damage (pp. 267-297). Baltimore: University Park Press.

TAYLOR, L. B. (1969). Localization of cerebral lesions by psychological testing. Clinical Neurology, 16, 169-287.

Teuber, H.-L. (1964). The riddle of frontal lobe function in man. In J. M. Warren \& K. Akert, (Eds.), Frontal granular cortex and behavior (pp. 410-444). New York: McGraw-Hill.

Walker, D. W., Barnes, D. E., Zornetzer, S. F., Hunter, B. E., \& Kubanis, P. (1980). Neuronal loss in hippocampus induced by prolonged ethanol consumption. Science, 209, 711-713.

WANBerG, K. W., Horn, J. L., \& FOSTER, F. M. (1977). A differential assessment model for alcoholism: The scales of the alcohol use inventory. Journal for Studies in Alcoholism, 38, 512-543.

(Manuscript received August 18, 1987; revision accepted for publication November 18, 1987). 